\title{
Urban Ecosystem Changes Around Natural Drains: Case of Becharji Nala of Vishwamitri River in Vadodara City
}

\author{
Munjal Mehta ${ }^{1}$ and Dimple Behal ${ }^{*}$ \\ ${ }^{1}$ Urban $\mathcal{E}$ Regional Planner, Parul University, India \\ ${ }^{2}$ Urban \& Regional Planner with Specialization in Environment, SPA Bhopal, India \\ *Corresponding author: dimplebeha19@gmail.com
}

Received: $11-10-2020$

Revised: $14-11-2020$

Accepted: 06-12-2020

\begin{abstract}
Water is an indispensable part of settlements and the human ecosystem. From the past, the civilizations have grown on the banks of rivers all over the globe providing drinking water, convenient transportation channels, and abundant natural landscapes and causing moderate temperature. Thus the river is this cities' most valuable natural resource". With the rapid urbanization, these natural ecosystems have been degraded immensely based on the growth potential of the settlements and have affected the population. India has seen an incredible growth in urban population over the last few decades and its urban population has grown 14-fold from 1901 to 2011. The growing population has a large impact on the natural ecosystem and urban water. The paper draws attention to one of the prevalent case study of Vishwamitri river in Vadodara, and how rapid changes in an urban area has affected the ecology of the river with a special focus on Becharji Nala, its consequences while recognizing the environmental legislation and recommends prompt considerations for defining the best protection procedures.
\end{abstract}

Keywords: Natural drain, Development Pressure, Environment Legislation, Development Plan, Water bodies

Water is part of a larger ecological system, a prime natural resource, a basic human need. Water is the cradle of civilization and, as such, is indispensable features of urban history. The civilizations have grown on the banks of perennial rivers all over the world. The dynamic and complex relationships between humans and water embedded in heterogeneous environments raise crucial questions about where humans reside in relation to water supplies. The relationship between human density and river distance was examined at a high world-wide spatially resolution, with a thicker population, rising river proximity but with regional variability based on climate, the degree of urbanization and history of economic growth (Adeloye, n.d.). Rivers are not only special areas of the city, but also the most representative regions representing local character. Sixty-nine large cities in the India are located on river banks with rivers providing drinking water, convenient transportation channel, and abundant natural landscapes and causing moderate temperature (Kothari \& Anitha, 2015). Thus, river is this cities' most valuable natural resource.

With population rising at an exponential pace almost all over the world, urban areas are growing much faster than rural areas. Although the rate of urbanization in India is among the lowest in the world, urban population growth in India has been extremely rapid over the course of this century. India, the leading country in South Asia, has seen an incredible growth in urban population

How to cite this article: Mehta, M. and Behal, D. (2020). Urban Ecosystem Changes Around Natural Drains: Case of Becharji Nala of Vishwamitri River in Vadodara City. Int. J. Soc. Sci., 9(04): 313-322. 
over the last few decades and its urban population has grown 14-fold from 1901 to 2011. However, in 2014, 54 percent of the world's population lived in urban areas, with two thirds projected to be urban by 2050 (Behal, 2020). According to the United Nations in2018, around 95 per cent of this development will occur in developing countries (Behal, 2020). The provisional results of the 2011 census show that over the decade, 2774 towns are emerging, including 242 statutory and 2532 census towns (MoHUA, 2020). In addition, UA has risen in the census from 35 million in the 2001 census to 53 in the 2011 census.

\section{Urbanization trends in Gujarat}

As urban population and land needs have faster than the conventional, a large number of river areas become occupied, leading rivers to deteriorate. In the early nineteenth century, the state of Gujarat witnessed similar rapid urbanization following the expansion of modern textile and railway industries, continued droughts in rural hinterlands and agricultural reforms, which contributed to rural population emigration to the cities.

It is projected that Gujarat will have $66 \%$ urbanization by the year 2030. Rural population in the state in 2011 fell to $57.4 \%$ from $62.6 \%$ in 2001 (Joshi, 2017). The state's urban population in Gujarat has been steadily growing since the independent state was created. The urbanization rate was substantially higher in the decade 1991-2001 and is projected to continue to be higher in the next two decades as calculated by the decadal growth of urban population. During the last five decades, urban population has increased almost five times in the State (from 5.31 million in 1961 to 25.71 million in 2011). This was the outcome of industrialization in the State, led by petrochemicals, pharmaceutical, textile, machine tools and other large industries. During 1984-89 drought periods, the migration from the arid zones of north Gujarat, Saurashtra and Kachchh increased towards the mainland cities such as Surat, Ahmedabad and Vadodara.

In 2001, over $50 \%$ of Gujarat's urban population concentrated in the seven towns listed as municipal corporations (Pandya Bhavini; Patel Madhukant, 2013).
When metropolitan agglomerations around these cities are taken into account, this urban population concentration rises to approximately 60 percent. Almost $40 \%$ of Gujarat's urban population lives solely in the three major cities of Ahmedabad, Surat and Vadodara. Gujarat is one of the fastest-growing urbanised states in the nation, as the population grows in urban areas. By the year 2011, about 42.5 per cent of the population was living in 30 cities with lakh plus cities and four million people plus cities of Gujarat. The National Commission on Population predicts the State population to reach about 50 per cent by the year 2025, which is also likely to be much earlier than projected. The present metropolitan cities Ahmedabad, Surat and Vadodara would cross population of $8.4,7.4$ and 4.2 million respectively by 2030 (Shashikant Kumar, 2002).

The Story of impact of urbanization in Gujarat is nothing new. Vishwamitri River is one such story of a degrading or dying river. Indiscriminate "housing development" in not only low lying areas and pits but also in the river bed itself, filling up ravines and the river bed with waste and debris, allowing slums to develop near river and above all local authorities turning a blind eye to all the activities happening near the river are effectively killing the river. These activities have obstructed the natural flow of rainwater. The river Vishwamitri that crosses Vadodara is also a natural habitat for many species of flora and fauna including crocodiles whose existence is threatened.

This study attempts to understand Vishwamitri River in its origin glory, resultant effects of Urbanization, the process of its degradation, general indifference among the community living on the river bank and the significant impacts of Urbanization on the river followed by Becharji Nala.

\section{City Profile}

Vadodara Urban Area is located in Vadodara district of Gujarat, situated in the fertile alluvial plains of MahiNarmada interfluves belt, encompassing an area of 714 $\mathrm{km}^{2}$ and 159.95 sq.kms. as the Municipal Jurisdiction area. Vadodara is located in the most developed region of the state of Gujarat, popularly known as "Golden Corridor" and lies between $73^{\circ} 5^{\prime}$ to $73^{\circ} 20^{\prime} \mathrm{E}$ and $22^{\circ} 10^{\prime}$ to 


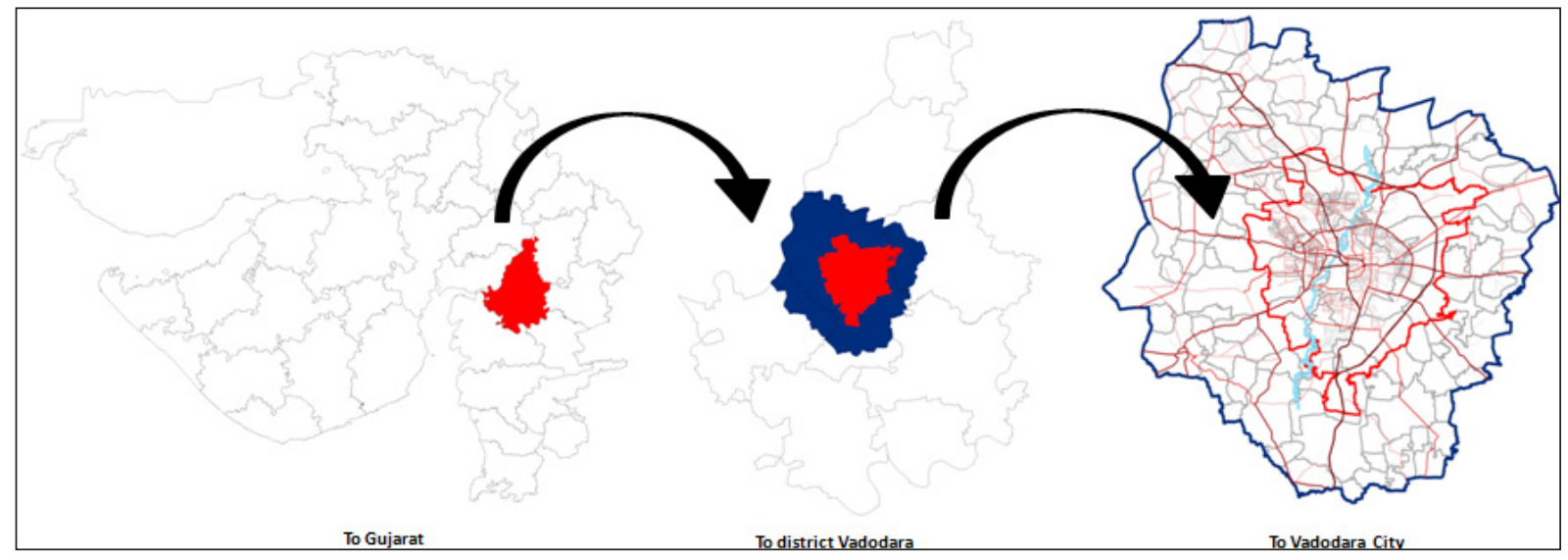

Fig. 1: Introduction to the City

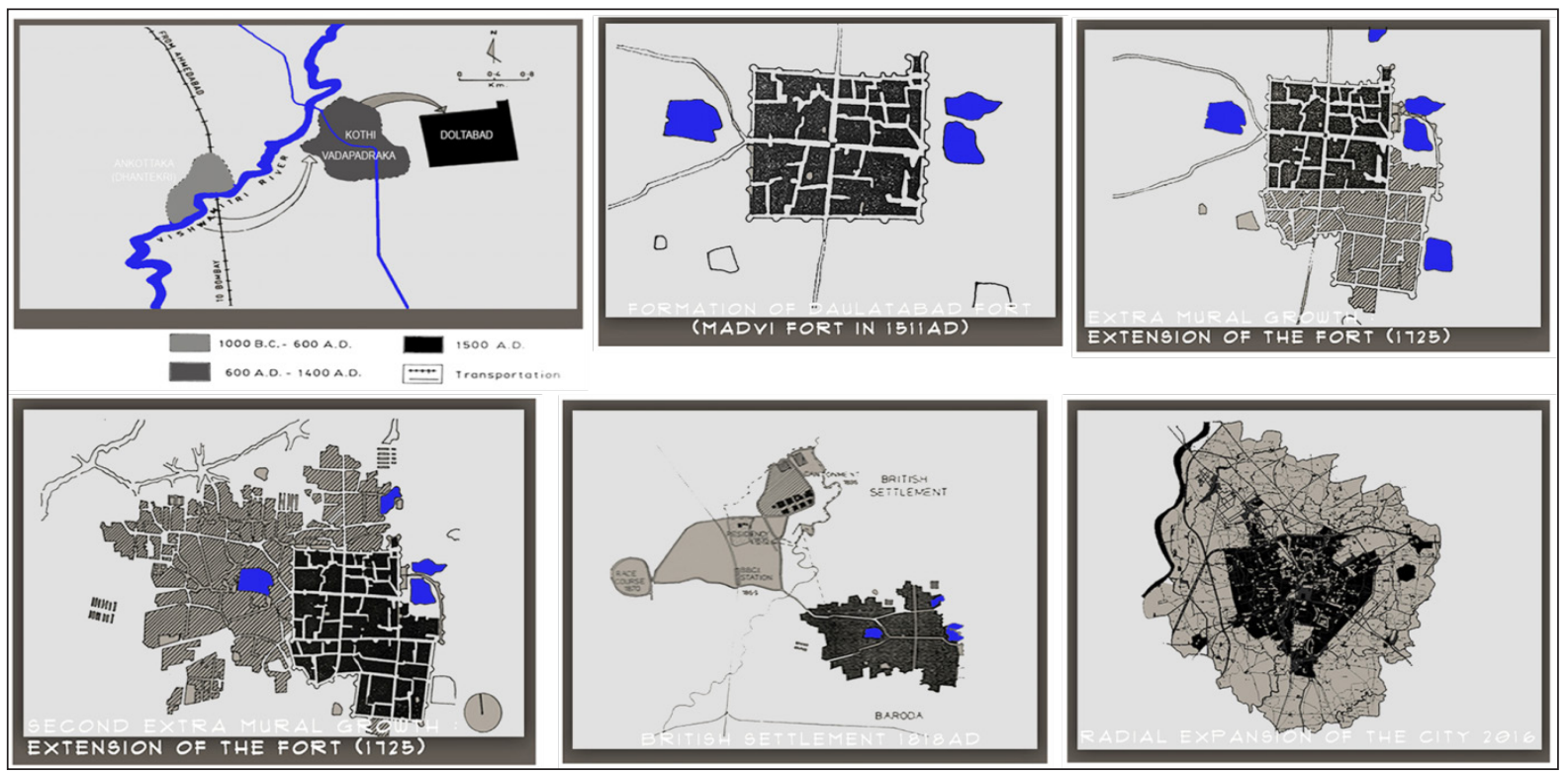

Fig. 2: Maps showing evolution of Vadodara along the river Vishwamitri

$22^{\circ} 28^{\prime} \mathrm{N}$ including the Vadodara Mahanagar Seva Sadan area and about 104 villages of Vadodara, Waghodia and Padra Taluka, of the district. It has the population of 16,66,495 as by Census 2011.

The city lies on either bank of the river Vishwamitri, which rises on the western slopes Pavagadh Hill, and joins the river Dhadhar after a very serpentine course at Pingalwara, about 15 miles southwest of Baroda.

\section{Geography}

Vadodara district has a flat terrain, with five rivers i.e.
Mahisagar in the north going along the boundary of the VUDA whereas the Mini, Vishvamitri, Surya Jambuvai and the Dhadhar flowing in the south. Apart from this there are smaller drains which cut across the landscape and form important part of the natural drainage system. This midland between the Mahi and Narmada covers the Baroda plain which is drained by tributaries of the Mahi, Narmada and Dhadhar. The river Vishwamitri is a dividing line between black soil sand red loams. Besides these rivers, the Jambuva and the Surya flow through the district and meet the Arabian Sea in the Gulf of Cambay. 
VUDA (Vadodara Urban Development Authority) has the rivers as Vishwamitri, Dhadhar and Jhambuvai (Tributary of Vishwamitri) while Vishwamitri and its tributaries could be seen in Municipal Jurisdiction area. Vadodara city has a general slope from east to west and north to southern and an elevation of 39 metres (123 feet). Under Koppen's Climate Classification, Vadodara offers a tropical Savannah climate. The Southwest Monsoon of the City of Vadodara (June-September). $47^{\circ} \mathrm{C}$ is the highest temperature reported and $15{ }^{\circ} \mathrm{C}$ is the lowest. In Vadodara, the average annual rainfall is $930 \mathrm{~mm}$. The natural stormwater drainage system is composed of the river Vishwamitri and another river Jambuva which joins the river Vishwamitri further southwards. City is also consists with number of man-made and natural water bodies.

\section{Urbanization and growth of Vadodara}

The name "Vadodara" has originated from the Gujarati word "Vad" which means Banyan tree. The city has many banyan trees growing along the road side thus revealing the name of the city. It is situated on the bank of Vishwamitri River and is also known as the "Cultural Capital" of Gujarat. Geographically the area is in between R. Mahi on the NW direction of Vadodara city and Vadsala village in the east and in north up to Jarod village and in south until Padra.

The Vishwamitri River was key element for the settlement of Vadodara, which was discovered on its banks in 1721. Later the city developed and got divided into eastern and western parts by River Vishwamitri which flows in north-south direction through the city. A very well planned network of Vishwamitri River, its tributaries (eg. Bhukhi Kans, Bahucharaji Kans) and "nallas"/channels and ponds forms a natural channel of water flow throughout the city that played an important role in reducing flooding/water-logging and recharging ground water that sustained the city.

The population of the city of Vadodara was about 1,126 million in 1991, rising to 1,491 million in 2001, 1,822 million in 2011, and 2,388 million in 2017. Vadodara city area was around $108.26 \mathrm{sq} . \mathrm{km}$. in 1991, which increases to 1113.87 sq. $\mathrm{km}$ in 2001, 159.31 sq. km. in 2011 \& with tremendous increase in the rate of urbanization it becomes around $400 \mathrm{sq} . \mathrm{km}$. in 2019.

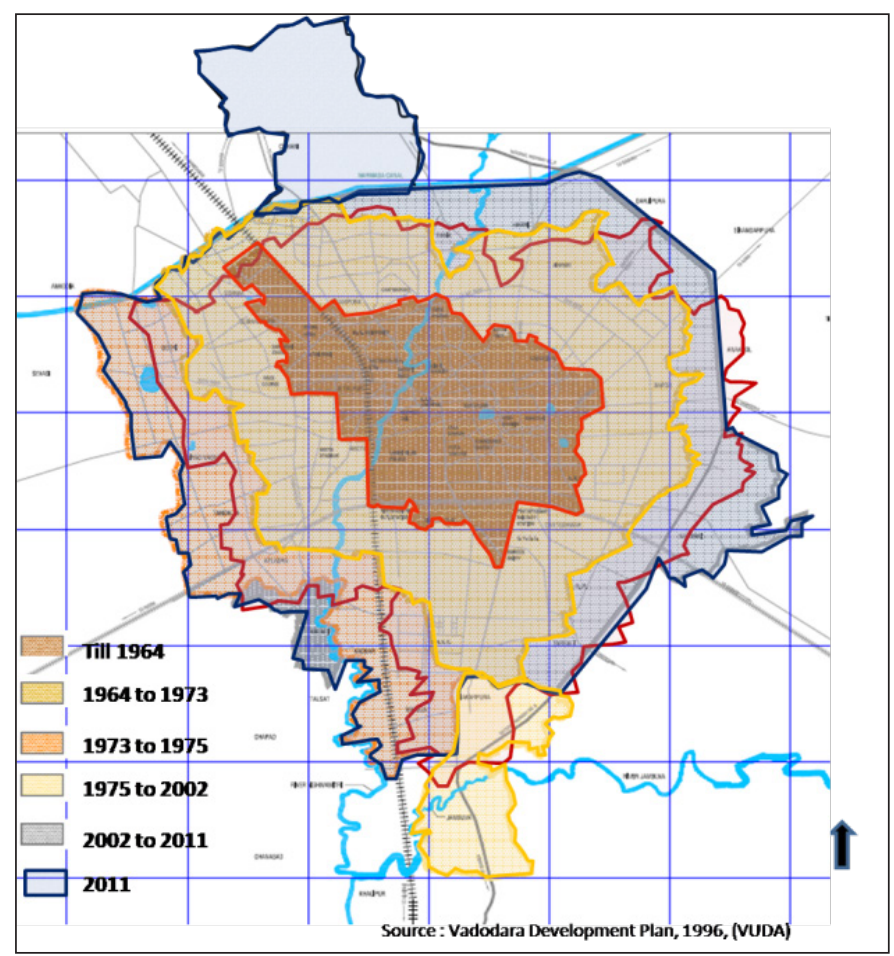

Fig. 3: Evolution of Vadodara Municipal Jurisdiction

Table 1: Population Growth of Vadodara (VUDA)

\begin{tabular}{lllll}
\hline Year & Population & Growth rate $\begin{array}{l}\text { Area (sq. } \\
\text { km) }\end{array}$ & $\begin{array}{l}\text { Density } \\
\text { (person/sq.km) }\end{array}$ \\
\hline 1991 & $1,126,800$ & $51.5 \%$ & 108.26 & 10408.28 \\
2001 & $1,491,045$ & $32.3 \%$ & 113.87 & 13094.27 \\
2011 & $1,822,221$ & $22.2 \%$ & 159.31 & 11438.21 \\
2019 & 2.388 million & - & 400.00 & 5970 \\
\hline
\end{tabular}

\section{Vishwamitri river and its significance in Vadodara}

The Vishwamitri River flows mainly from the Pavagadh district of Panchmahal in Gujarat, to the west of the city of Vadodara. The Vishwamitri Basin, situated in the eastern part of Gujarat and stretches into 3423 square $\mathrm{km}$, forms part of the Dhadhar Basin. The river's length from the head to the Dhadhar is approximately 80 kilometres. The maximum river area protected by the project impact area is 598 square metres. Kilometers. The name of this river is said to be derived from the name of Vishwamitra the great saint. It fuses to the 

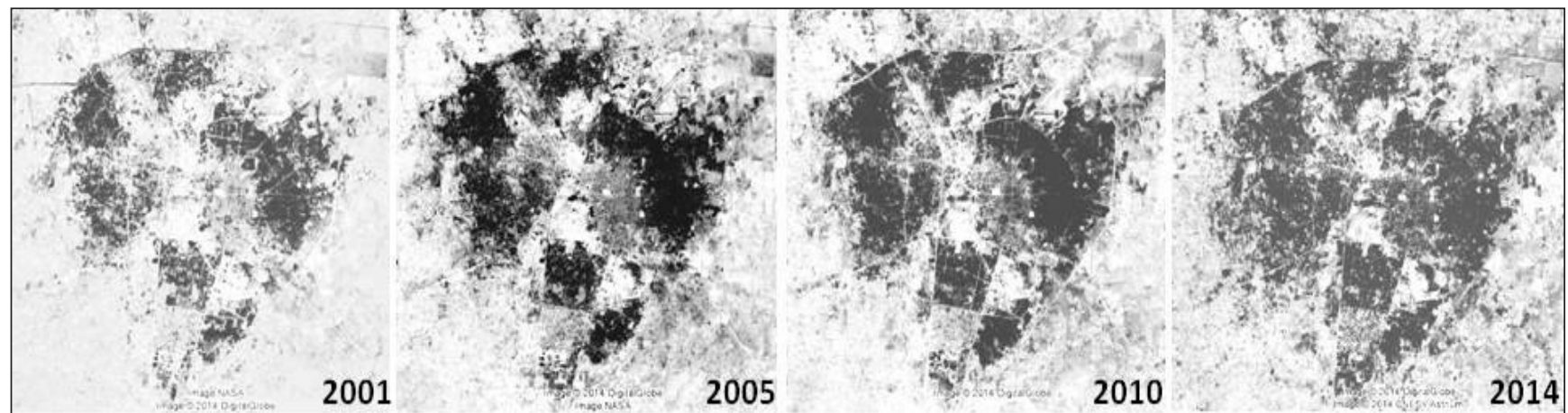

Fig. 4: Built-up increase in Vadodara

Gulf of Khambhat into two other tributaries, namely Dhadhar and Khanpur. A human settlement dated 1000 B.C was discovered on the bank of the Vishwamitri River, which confirms the existence of the Stone Age period. At the beginning of the Christian era, a small city was also built on a mound on this river, later known as Ankotakka (currently referred to as Akota) while the Dhantekri mountain is known. It was created by the removal of grasslands and dense forests covering an area of 0.5 to 0.75 sq. Kilometers. The Vishwamitri River was the gateway to Vadodara's settlement, which was established in 1721 on its banks.

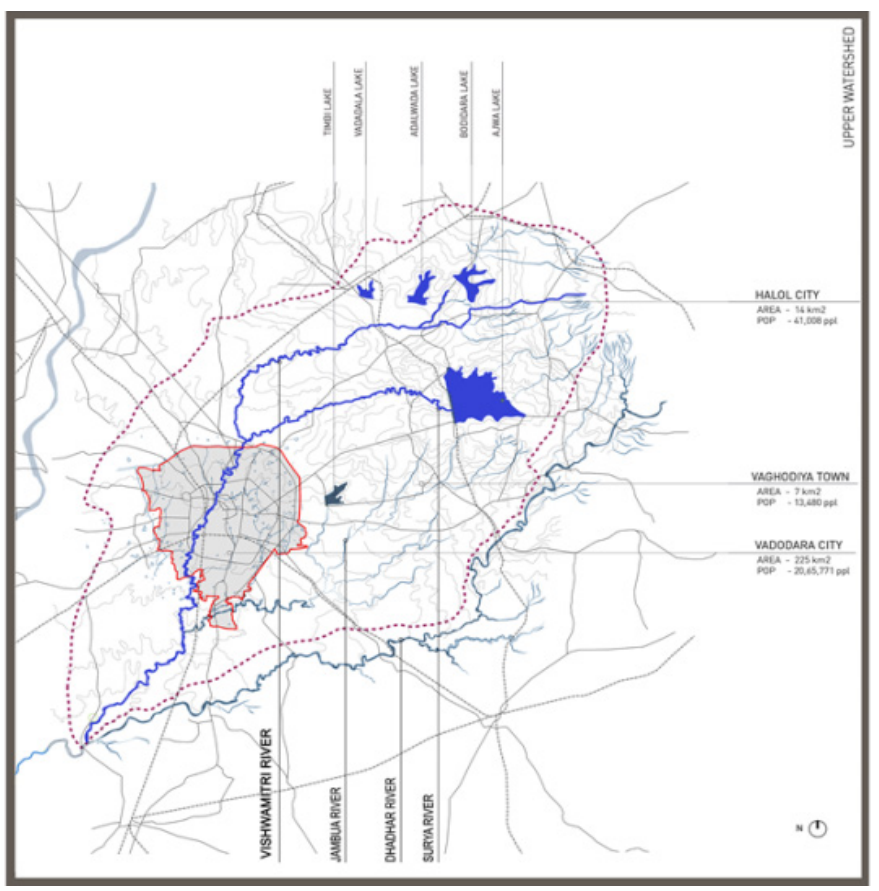

Fig. 5: Origin and route of Vishwamitri River
Three major tributaries are present in this river system: Vishwamitri, Dhadhar and Jambuva. These three tributaries come from the hills of Pavagadh and the forests of Jambughoda. About three and a half miles upstream from Baroda this river is joined by a stream called Surya or Surva. These rivers have cut deeply incised valleys into the soft alluvium, through which they flow. The Sayaji Sarovar on the Vishwamitri River near Ajwa and the Dev Dam on the Dhadhar Branch are included in this river system. Its flow is between two large perennial rivers, Mahi and Narmada, from east to west. At the NH-48 crossing, the Vishwamitri River enters Vadodara City and flows across the city up to Atladra Bridge. Approximately $25 \mathrm{~km}$ of river passes through the city of Vadodara and bisects the city. The banks of the Vishwamitri River are home to many historical places such as Chhatri, Pratappura Sarovar, Old Bridge, Suspension Bridge, Boat House, etc. Vishwamitri is one of the endangered reptile species in India, the home of the mugger or marsh crocodiles.

The Vishwamitri River is a seasonal, west flowing river between the Mahi and Narmada rivers in Gujarat state. After flowing $80 \mathrm{~km}$ the river meets Dhadhar tributary on the right bank at Pingalwada village $500 \mathrm{~m}$ up stream of gauge and discharge site. After flowing another 55 $\mathrm{km}$ it falls into the Gulf of Khambat. The important tributaries of the Vishwamitri River are Surya, Jambuva River and Bhukhi River. Surya River joins at Dena village before entering Vadodara and Jambua river joins at Jaas village near Khalipur after leaving Vadodara.

The city had channels draining into the river Vishwamitri. These served as escape route for flood waters and carried 
away excess water into the river preventing flooding. Natural streams, locally called nallas interlinked various major ponds and finally emptied into the river Vishwamitri. In the city there existed 4 nallas to drain storm water viz.

1. Ruparel Nalla (stream) passes through Waghodia road, Paniget, Wadi, ONGC, Tarsali, Makarpura and finally meet Vishwamitri through Jambua river in the South of the City. It was connected to several water bodies like Warasiya, Sarasia, Ajabdi, Raje, Sursagar and Mohammed tank with small nallas in the past. Reclamation and blockages has discontinued this link.

2. The Bahucharaji Nalla (stream) starts from overflow of Warasiya ponds and meets Vishwamitri near Sayajigunj, draining through Fatehpura, Harni, Karelibaug etc.

3. The Bhuki Kotar Nalla (stream) drains through Channi, Sayajigunj, and University area and meets Vishwamitri at Sayajigunj near Kalaghoda.

4. Another Nalla (stream) collecting storm water from Gorwa, Gotri and Atladra area and meet Vishwamitri in South of the city.

Uniqueness of Vishwamitri (in Vadodara):

1. 7 Kaanz (local name for Channel) including Bhuki Nala, 3 dried and 4 functional.

2. 32 water bodies : 19 functional and 8 non functional.

3. Habitat of Crocodiles.

\section{Urbanization and its effects on Vishwamitri river/ Becharji Nala}

The city of Vadodara has undergone lot of change in its natural Land Form, Land Cover, and Land Use to meet the demand of urbanization which has also altered the structure and function of the ecosystems of the urban area. The city of Vadodara, an urban centre between Surat and Ahmadabad, is third largest city and has potential to develop at fast rate after development of Delhi Mumbai Industrial Corridor (DMIC).

The Story of Vishwamitri River is one such story of a degrading or dying river. Indiscriminate "housing development" in not only low lying areas and pits but also in the river bed itself, filling up ravines and the river bed with waste and debris, allowing slums to develop near river and above all local authorities turning a blind eye to all the activities happening near the river are effectively killing the river. The rising population and advanced living standards have resulted in a growing demand for residential land in both villages and cities. Vadodara City is obligated to grow vertically rather than horizontally. Inability to address the increasing demand for infrastructure in the city had made more and more people being forced to stay near river banks. As a result of this, large numbers of human settlements have emerged on and near banks. Slum settlements have been overlooked as they became part of developmental strategies in Vadodara. Municipal authorities in charge of solid waste management pay little attention to urban drainage systems even though uncollected garbage

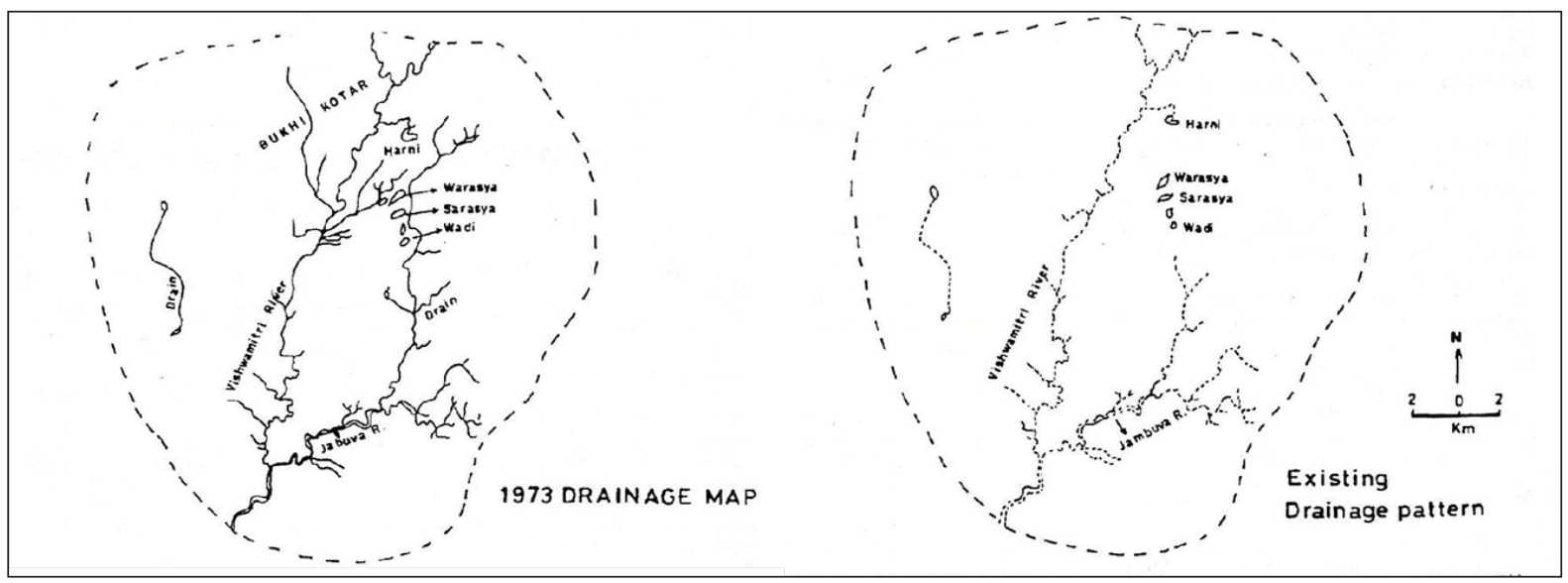

Fig. 6: Drainage Pattern of Vishwamitri river 
is most often the cause of blockages which obstructs the natural course of the river. These activities have obstructed the natural flow of rainwater and the result is, even a downpour of 5 inches water floods the city of Vadodara.

The Vishwamitri River portion that passes through Vadodara is also a natural habitat for many species of flora and fauna, including crocodiles that are endangered by their presence. These ecosystems provided many services for human well-being and sustainability like flood regulation, water quality and quantity control, vegetation, water logging, microclimate etc. With the impact of urbanization, there is a change in structure and function of these urban ecosystems affecting its service provisioning. This the city is undergoing many urban issues like Urban floods, water logging in many areas as road network does not consider the natural topography causing the disturbance in drainage pattern and hence rainwater drainage. Also in order to mitigate the demand of water for the industry and households, there is a lot of groundwater extraction of groundwater but no recharge because of increased impermeable surface adding to the severity of the issue causing the change in quantity and quality of water in aquifers within last decade.

\section{Impact of Urbanization on Bahucharji Nala of Vishwamitri river}

The rapid change in land use pattern over last couple of decades due to urbanization has emerged as a major cause of urban flooding in Vadodara. Increasing unplanned construction in the low elevation areas and river banks, depletion of water bodies, encroachment of river banks by slums and the conversion of land for agriculture to a large extent are the major land use changes responsible for frequent flooding in the city. The prevalence of slums has greatly increased throughout the city, especially along the banks of the Vishwamitri River, reducing the river's width. Not just that, unplanned construction around low lying zones, obstructing the flow of water into the sinks is causing water logging in most of the areas in Vadodara.

Development and industrialization also exert strain on the riverine system that degrades the rivers' serenity.
The spatial variation in the rate of pollution in the river stretch was explored in a report on the Vishwamitri River. There was a substantial difference between the water and soil quality of the river before entering the city of Vadodara and after leaving the city limits. The disparity observed is directly associated with the amount of sewage entering the river from the city at various points and the dumping of solid waste carried out on its banks. The total generation of domestic sewage from Vadodara city is approximately 215 MLD, of which only 180 MLD of sewage is being treated. The waste water, processed and untreated, is released into the river. The sewage treatment capacity of approximately 215 MLD was established by Vadodara Municipal Corporation, of which 180 MLD is used as a sewage collection facility. The contribution of industrial sources is estimated at approximately 20-25 MLD, of which two industrial areas are handled by CETPs for their waste water (capacity 7.75 MLD). Some companies have their own treatment plants to treat their waste water. However, in residential areas, there are a large number of small-scale enterprises that produce substantial quantities of waste water and do not have any treatment plants.

The waste water from these sectors is released into the sewerage system of the VMC. As the network does not exist or is insufficient, sewage is redirected into the natural drains. The lines are connected to these nallahs as a temporary measure to prevent sewage flooding in the streets and lanes. Hence, the network needs to be isolated and diverted to STP as a priority measure. The pollution that results in Vishwamitri is primarily due to the untreated sewage that reaches the $21-\mathrm{km}$ odd meandering stretch of the river in the city at different points. Often, because the river is seasonal, for much of the year the water flowing in the river is nothing but waste let out. The water in the downstream area is used by the adjoining farms for irrigation purposes. The lack of storm water drains often contributes to sewers overflowing and regular cleaning and repair. The overflowing sewage also makes its way to the bodies of the river/nallah/water. Consequently, in the sewers, rain water is also let out. Therefore, one of the department's prime targets is to distinguish waste from storm water. The newly built areas of the city were not reached by 
$\underset{\text { AESSRA }}{\sqrt{4}}$ Mehta and Behal

the sewerage system. Sewage from this area needs to be collected and transported to the site of the treatment plant and processed until it is released into the water.

Presently, in Vadodara, many landscape architecture initiatives blindly follow the beautification trend and merely seek modernization. This strategy lacks individuality and character, choosing homogeneity over the inherent consistency that distinguishes Vadodara. It appears to neglect local features. Without detailed planning direction, solid concept and simple design themes, the city's riverfront projects are hastily built square green spaces along river fronts while ignoring the possible tension between modernism and local culture. Riverfronts usually have rich historical resources and heritage; however, traditional culture and local characteristics have been overlooked in the application by many new riverfront projects. In the meantime, the architecture and planning of the urban riverfront can not be mixed well with conventional culture. Instead of being removed from the original material carriers, some buildings are restored, which destroys a significant number of old buildings. Moreover, existing buildings or sites are not taken into account by local architects who plan large scale project, which seriously ruins the original riverfront features and profiles, and artificially divides the city's spatial shape. The Bahucharaji stream is one such example. The stream is encroached by slums due to which congestion of the stream in the downstream do not allow storm water to pass quickly. During the monsoon when stream overflows water inundates the surrounding area in Fathepura. Bahucharaji drain, which passes through the area, is encroached by the slum dwellers and appears as a sewage drain. At various points VMC dumps solid waste into the drain. Due to dumping activity the nalla has been reduced further and blocked at various places. When the storm water flushes, the slum dwellers are the first to be affected and have to evacuate because they reside on nalla bed. As the width of the nalla has been reduced and blocked at

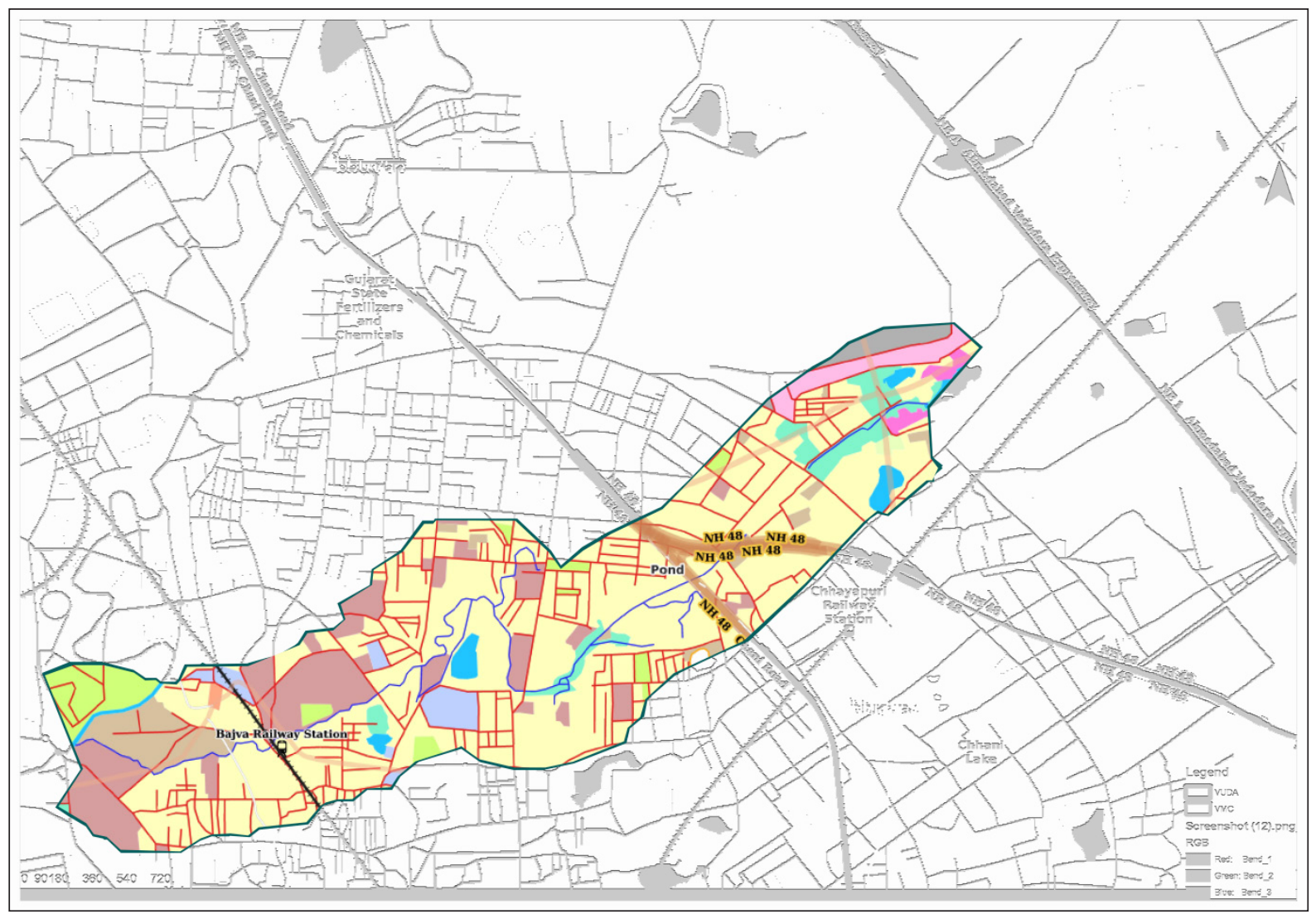

Fig. 7: Land use along Becharji Nala, Vishwamitri river 
various places, smooth flow of water into Vishwamitri is hindered resulting in flooding of upper region, viz. Bhutdizampa and Hathikana.

ULB has and continues to permit demolition, tree felling and vegetation clearing, debris dumping, untreated sewage discharge, dredging, digging, filling, levelling, building, etc. activities along and around the Vishwamitri River and its surroundings (banks, ravines, tributaries, ponds, wetlands, etc.). Extreme and mindless disturbances take place on the banks of the Bahucharaji Nala in relation to natural land types, soils, and hydrological regimes coupled with the removal of vegetation, including important trees.

\section{Consequences of development Pressure on Becharji Nala}

* Due to significant development pressure, the waterbody have been disconnected and begun to dry.

* Unchecked development along Becharaji Nala has caused encroachment at few points.

* Due to these encroachment, the runoff water becomes stagnant in the Nala and it causes floods.

* Also, the residential waste are dumped in the Nala causing blockages.

* Furthermore, few crocodiles were spotted by the locals in this Nala which shows richness in ecology but this is disturbed with the rapid development.

* With these floods, crocodile and other such organisms could be life threatening for the residents living around the Nala.

* The stagnant water may cause serious health hazards for the locals due to unsanitary condition of Nala.

The point to consider is that, activities around the river are in violation of the order of the High Court of Gujarat dated 2 February 2002, the provisional order of the National Green Tribunal dated 25 May 2016, and the order of the Supreme Court dated 22 February 2017.

In addition, certain works and practices are in complete violation of the terms of the following environmental legislation:
* The Wildlife (Protection) Act 1972

* Environmental Impact Assessment Notification, 2006 under the Environment (Protection) Act 1986.

* The Environment (Protection) Act 1986.

* The Wetlands (Conservation and Management) Rules 2010.

* The Solid Waste Management Rules, 2016.

* The Construction and Demolition Waste Management Rules, 2016.

Not just that, within the city premises, no provision of Becharaji Nala in any Development Plan is there since 2001.

The Municipal Corporation of Vadodara shall retain the status quo and shall not perform further activities for construction or development in the area of the Vishwamitri Riverfront Development Project until prior environmental clearance in the area of that project is obtained." This also contravene the High Court Order of Gujarat in SCA No. 19621/2000 of August 22, 2002: "Care will be taken that water bodies are not converted to any other use in the town planning schemes / development plans that may be made hereafter and the Local Authorities and the Area development Authorities will be instructed to ensure that no debris of buildings is dumped by any person or institution in the existing water bodies".

\section{CONCLUSION}

Water is a scarce and precious national resource to be planned, developed, conserved and managed on an integrated and environmentally sound basis, keeping in view the socio-economic aspects and needs of the area. Hence, it is imperative to respect nature and give its own space. Anthropogenic activities have accelerated the risk and have made the settlements more vulnerable. If not, there might be indirect or direct consequences. Urbanization, though have positive impacts on human lives, is affecting environment in a negative way and consequences could be seen in terms of natural disasters, climate change and much more. Degradation of natural ecosystem would result in loss of biodiversity, intangible heritage, livelihood and much more. Certain 
laws and policies are mandated to be adopted nationally and internationally to protect the environment but it is the responsibility of the institutions as well as citizens to make sure they are followed. Development and Environment should go hand in hand for better living indices of population, otherwise the results would be devastating.

\section{REFERENCES}

Urban Growth. (n.d.). Retrieved from MoHUA website: http:// mohua.gov.in/cms/urban-growth.php

Adeloye, A. J. (n.d.). Rivers and human development.

Behal, D. 2020. Why rapid urbanisation in peri-urban areas is a concern for Chandigarh. Retrieved from Down-to-Earth website: https://www.downtoearth.org.in/blog/agriculture/ why-rapid-urbanisation-in-peri-urban-areas-is-a-concern-forchandigarh-71197

Deota, B., Dholakia, A. and Desai, N.D. 1997. Vadodara Floods: A case study of unplanned urbanization.

Gosai, D.P., Joshi, G.S., Prakash, I. and Patel, A. 2016. Assessment of Flood Potential in Vishwamitri River Basin Using Remote Sensing \& GIS, Gujarat. National Conference on Recent Advances in Civil Engineering (RACE2016), (March).

Joshi, J.P. 2017. Modelling Urban Sprawl Dynamics for Vadodara Urban Region Integrating Cellular Automata \& GIS.
Kothari, N. and Anitha, T. 2015. Reviving Vishwamitri River: an effort to a Sustainable Impact. Retrieved from http://27.109.7.66:8080/xmlui/bitstream/handle/123456789/ 129/PPS04.pdf?sequence $=1 \&$ isAllowed $=y$

Kushang, V. and Suvarna, D. 2017. Urban Stormwater Management Policy- Linking of Urban lakes for West Part of Vadodara City. International Journal of Technical Innovation in Modern Engineering \& Science, 3(04): 229-240.

Padalia, C.V., Raval, T.A., Parekh, F.P. and Suryanarayana, T.M.V. 2017. Comparison of Water Level of Natural and Modified Section of Vishwamitri River using. International Journal of Engineering Trends and Technology (IJETT), 47(6): 329-335.

Bhavini, P. and Patel, M. 2013. Economic Growth and Pattern of Urbanization in Gujarat D. (April), 2001-2003.

Sharma, D., Gavali, D. and Lakhmapurkar, J. 2004. Wetland Degradation and Water Logging in Vadodara City Wetland Degradation and Water Logging in Vadodara City. https://doi. org/10.13140/RG.2.2.12815.89769

Kumar, S. 2002. An investigation of the dynamics of development planning and its integration with regional planning approach: a geographical study of Gujarat state 1951 2002. Retrieved from http://hdl.handle.net/10603/36668

Shastri, H.K., Desai, D.B. and Parthsarthy, G.S. 2005. Blockage of Natural Drains Due to Urbanisation and its Afterfits. 